\title{
DIFERENÇAS DE REGIMES HÍDRICOS (DINÂMICA DA UMECTAÇÃO E DE SECAGEM) DOS DOIS SOLOS MAIS FREQUENTES NO SUDESTE PARAENSE (LATOSSOLO E ARGISSOLO) EM CONDIÇÕES NATURAIS
}

\author{
Deise Laiana da Silva Barbosa ${ }^{1}$; Michel Grimaldi ${ }^{2}$ \\ ${ }^{1}$ Discente do curso de Agronomia, Faculdade de Ciências Agrárias de Marabá (FCAM), Universidade Federal do Pará \\ (UFPA), Marabá, Pará. Bolsista do projeto AMAZ. E-mail: deise-23@ hotmail.com \\ ${ }^{2}$ Pesquisador do IRD - Institut de Recherche pour le Développment. E-mail: michel.grimaldi@ird.fr
}

RESUMO: As relações e reações que ocorrem no sistema dinâmico solo-planta-atmosfera funcionam de forma articulada buscando um equilíbrio e um auto-regulamento. Dentro desse sistema a água atua na manutenção, o solo entra como reservatório temporário e a disponibilidade da água torna-se uma variável devido à descontinuidade das chuvas e às perdas diversas. As propriedades físicas do solo (textura, estrutura) determinam a disponibilidade e os fluxos da água nos solos. O processo de secagem, apesar de ser pouco estudado, tem sua importância na compreensão dos processos de infiltração, redistribuição e suprimento de água pelas plantas. Dessa forma faz-se necessário o entendimento das condições climáticas como um todo, para que o uso racional do solo juntamente com a disponibilidade hídrica possa ser contemplado em trabalhos de levantamento das possibilidades e limitações da agricultura. Este trabalho tem como objetivo caracterizar o funcionamento hídrico de um Latossolo e um Argissolo, desenvolvidos sobre a mesma rocha e nas mesmas condições de vegetação (floresta) e relevo, e comparar com outras condições de meio biofísico encontradas na Amazônia, e trás como hipótese que tais solos apresentam comportamentos distintos, devido à diferença de organização estrutural que estes possuem. A partir de tradagens em período chuvoso, serão identificados os dois tipos de solos e determinodos dois pontos, M3ZC4 e M3ZC5, no lote do senhor José Claudio no PA Agroextrativista Praialta-Piranheira. Tensiômetros serão instalados nos dois pontos em oito profundidades: $10,20,30,50,70,90,120$ e 150 centímetros, para medir o potencial da água no solo. Ao lado dos tensiômetros será medida a umidade volumétrica nas profundidades de 0 a 160 centímetros com uma sonda TDR (Time domain reflectometry). Nos dois pontos serão feitos também testes de infiltração na camada superficial do solo pelo Método Beerkan simplificado com quatro repetições. A densidade aparente do solo também será medida em cinco profundidades (0-2, 2-5, 5-10, 15-20, 20-25 centímetros) com quatro repetições. Quatro trincheiras serão abertas para caracterizar o estado físico da camada superficial dos solos $(0$ a $25 \mathrm{~cm})$. Será aberta uma trincheira de 1,5 $\mathrm{m}$ de profundidade em cada ponto, para caracterizar as propriedades físicas dos horizontes, a partir de amostras analisadas no laboratório de Agronomia da Universidade Federal Rural da Amazônia - UFRA (granulométria, curvas de retenção da água) e de medidas feitas no campo com o teste de infiltração Beerkan para estimar a condutividade hidráulica dos solos. Com esses dados é possível comparar as propriedades físicas dos horizontes nos dois tipos de solo e seguir seu funcionamento hídrico nas mesmas condições climáticas e de cobertura vegetal, em particular a drenagem da água das chuvas e posteriormente a secagem do solo a partir do início da estação seca. Espera-se ampliar o conhecimento das propriedades físicas e do funcionamento hídrico do Argissolo e do Latossolo em condições naturais de floresta, para servir de referência a pesquisas, que busquem avaliar os impactos que as mudanças de cobertura vegetal podem exercer sobre o regime hídrico dos solos da região sudeste do Pará ou ainda de outra região que apresente semelhante situação.

PALAVRAS-CHAVE: Propriedades hidráulicas do solo, tensiômetros, TDR. 